\title{
'n Ondersoek na die gebruik van musiek as 'n deel van die pastorale begeleiding van die adolessent
}

\begin{tabular}{|c|c|}
\hline \multicolumn{2}{|c|}{$\begin{array}{l}\text { Authors: } \\
\text { Amanda L. du Plessis }{ }^{1} \\
\text { Janene de Beer }\end{array}$} \\
\hline \multicolumn{2}{|c|}{$\begin{array}{l}\text { Affiliations: } \\
{ }^{1} \text { Department Practical } \\
\text { Theology, North-West } \\
\text { University, Potchefstroom } \\
\text { campus, South Africa }\end{array}$} \\
\hline \multicolumn{2}{|c|}{$\begin{array}{l}\text { Correspondence to: } \\
\text { Amanda du Plessis }\end{array}$} \\
\hline \multicolumn{2}{|c|}{$\begin{array}{l}\text { Email: } \\
\text { amanda.duplessis@nwu. } \\
\text { ac.za }\end{array}$} \\
\hline \multicolumn{2}{|c|}{$\begin{array}{l}\text { Postal address: } \\
\text { Private Bag X6001, } \\
\text { Potchefstroom 2520, } \\
\text { South Africa }\end{array}$} \\
\hline \multicolumn{2}{|c|}{$\begin{array}{l}\text { Dates: } \\
\text { Received: } 16 \text { Aug. } 2012 \\
\text { Accepted: } 18 \text { Sept. } 2013 \\
\text { Published: } 14 \text { Feb. } 2014\end{array}$} \\
\hline \multicolumn{2}{|c|}{$\begin{array}{l}\text { How to cite this article: } \\
\text { Du Plessis, A.L. \& De Beer, J., } \\
2014, \text { 'n Ondersoek na die } \\
\text { gebruik van musiek as 'n deel } \\
\text { van die pastorale begeleiding } \\
\text { van die adolessent', Verbum } \\
\text { et Ecclesia } 35(1) \text {, Art. \#779, } \\
8 \text { pages. http://dx.doi. } \\
\text { org/10.4102/ve.v35i1.779 }\end{array}$} \\
\hline \multicolumn{2}{|c|}{$\begin{array}{l}\text { Note: } \\
\text { This article was presente } \\
\text { at the International Child } \\
\text { and youth conference, } \\
\text { North-West University, } \\
\text { Potchefstroom, 26-28 } \\
\text { September 2012. }\end{array}$} \\
\hline \multicolumn{2}{|c|}{$\begin{array}{l}\text { Copyright: } \\
\text { (C) 2014. The Authors. } \\
\text { Licensee: AOSIS } \\
\text { OpenJournals. This work } \\
\text { is licensed under the } \\
\text { Creative Commons } \\
\text { Attribution License. }\end{array}$} \\
\hline \multicolumn{2}{|l|}{ Read online: } \\
\hline 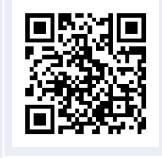 & $\begin{array}{l}\text { Scan this QR } \\
\text { code with your } \\
\text { smart phone or } \\
\text { mobile device } \\
\text { to read online. }\end{array}$ \\
\hline
\end{tabular}

An investigation into the use of music as a part of pastoral counselling of the adolescent. Pastoral counselling of the adolescent could be a challenge, because adolescence is a period characterised by emotional fluctuation. During this period of the individual's life, he or she begins to form his or her own identity and searches for a place in society, apart from the protection of their parents. Adolescents often do not have the necessary skills to deal with repressed emotions. Research shows that music has been used for many centuries in the healing process and that it has had a great influence on the psyche of human beings. For this reason, music can play an effective role in counselling adolescents. Music therapy involves the structural use of music and/or musical elements like rhythm, melody and harmony.

\section{Inleiding}

Die psigiater Armand Nicholi (Collins 1988:167) beskryf adolessensie as die 'verwarrendste, uitdagendste, frustreerendste en mees fassinerende fase van menslike ontwikkeling'. Die woord adolessensie verwys na die tydperk in 'n persoon se lewe wanneer hy of sy van 'n kind tot 'n volwassene ontwikkel. Volgens die model van Erickson (Robbins 2004:225) begin adolessensie met puberteit (op ongeveer 12 jaar) en strek dit tot die laat tienerjare (ongeveer 18 jaar) of vroeë volwassenheid (sover as 28 jaar). Tydens hierdie tyd van konflik en groei vind fisiese, seksuele, emosionele, intellektuele en sosiale veranderings in jongmense plaas (Collins 1988:168). Elke adolessent worstel met vier deurslaggewende vrae, naamlik 'Wie is ek?', 'Hoe kom ek oor die weg met ander mense?', 'Waar pas ek in?' en 'Wat glo ek?' Dit is dus 'n tydperk wanneer die adolessent op soek is na 'n eie identiteit en plek in die samelewing. Volgens Robbins (2004:226) is adolessensie ook die tydperk wanneer die epigenetiese aard van die ontwikkeling van die adolessent se persoonlikheid waargeneem kan word, omdat dit in hierdie fase is dat die vrugte van gebeure in die vroeëre ontwikkelingstadiums gesien word. Wanneer die kind in gesonde huislike omstandighede grootword, word 'n stewige fondament gelê vir die vorming van sy of haar identiteit, maar die teendeel is ook waar. Die druk wat met adolessensie gepaard gaan, eis soms sy tol, veral in die geval waar die persoon met onverwerkte, onderdrukte emosies worstel. Onsekerheid, skuldgevoelens, minderwaardigheid, eensaamheid en verwerping kan tot diep in die volwasse jare voortduur indien die adolessent nie gehelp word om die emosies te herken en te verwerk nie.

In terapeutiese hulpverlening aan die adolessent is daar volgens North, Hargreaves en $\mathrm{O}^{\prime}$ Neil (2000:255) vasgestel dat musiek ${ }^{1}$ 'n uiters belangrike rol in die lewe van die adolessent speel, omdat musiek dikwels in sy of haar emosionele behoeftes voorsien. Volgens Mueller (1999:65) draai die lewe van die adolessent om musiek. Musiek is 'n kragtige middel wat gebruik kan word om emosies te verken en te verwoord (Danley-Smith \& Patey 2003:7-8). Die persoonlike getuienis van die musikant Trent Reznor, van die popgroep Nine Inch Nail, is 'n raak beskrywing van die waarde van musiek vir die adolessent: 'Rock and roll helped give me my sense of identity' (Mueller 1999:67). Musikante soos Trent Reznor besef dat musiek dit vir 'n mens moontlik maak om die adolessent op sy of haar eie ontwikkelingspeil te ontmoet en hul vrae op opwindende en aanloklike maniere deur lirieke en musiekvideo's te ondersoek. Musiek in al sy verskillende vorme het 'n groot invloed op die ontwikkeling van die selfkonsep van die adolessent (Kistler et al. 2010:617). Vanaf 'n vroeë ouderdom word adolessente onbewustelik deur musiekonderrig in die vorming van hul lewensbeskouing, waardes en gesindhede (Mueller 1999:68).

In die lig van die inleidende opmerkings word die volgende navorsingsvraag ondersoek: Hoe kan musiek in die pastorale begeleiding van die adolessent as ' $n$ beradingstegniek gebruik word? Om hierdie vraag te beantwoord, word 'n literêre studie in die betrokke vakwetenskappe onderneem met die klem op die ontwikkeling en aktualiteit van musiek as 'n beradingstegniek

1.Die vraag ontstaan dadelik na watter musiek verwys word. Kan die musiek enige soort musiek wees, dus enigiets van hard rock to hoogs klassiek? Word alle soorte musiek in musiekterapie gebruik? Hierdie vrae word in die artikel bespreek. 
in die pastorale begeleidingsproses. Daarna word riglyne vir die gebruik van musiek in die pastorale begeleidingsproses voorgestel. Hierdie proses sluit aan by Osmer (2008) se vier take vir die metodolgie van die wetenskapsbeoefening van Praktiese Teologie:

- Eerstens word daar op die empiriese aspekte gelet. (Wat is die invloed van musiek op die lewe van die adolessent?) Hierdie aspek word onder 'Die invloed van musiek op die adolessent' bespreek, waar die gevallestudie van Stacey weergegee word.

- Tweedens verskuif die klem na die interpretatiewe aspekte. (Hoekom het musiek so 'n groot uitwerking op die lewe van die adolessent?) Hierdie aspek word onder die tweede deel van 'Die uitwerking op en bydrae van musiek tot die adolessent se lewe' bespreek.

- Derdens val die soeklig op die normatiewe aspekte. (Watter norme kan uit 'n kort oorsig van die gebruik van musiek in die Bybel afgelei word?) Hierdie aspek word onder die eerste deel van 'Die uitwerking op en bydrae van musiek tot die adolessent se lewe' bespreek.

- Laastens word daar op die pragmatiese aspekte gekonsentreer. (Hoe moet die pastorale berader musiek as 'n deel van die pastorale begeleidingsproses aanwend?) Hierdie aspek word onder 'Musiek as 'n deel van die pastorale begeleidingsproses van die adolessent' behandel.

\section{Die invloed van musiek op die lewe van die adolessent}

Volgens Wright (2003:405) is die grootste uitdaging vir die pastorale berader wat adolessente begelei om nie van hul jong kliënte te verwag om emosionele probleme soos volwassenes te hanteer nie. Die rede daarvoor is bloot dat die adolessent nog nie oor die vaardighede beskik om dit te doen nie. Die pastorale berader behoort 'n goed ontwikkelde vermoë te hê om op die vlak van die adolessent met hom of haar in verhouding te tree. Die pastorale berader mag nie wegskram van die manier waarop die adolessent aan sy of haar emosies uiting gee (of nie gee nie); trouens, die berader moet juis die uitingsvorm as 'n leidraad benut om die mees geskikte tegnieke uit die beskikbare beradingstegnieke te selekteer en toe te pas om tot die emosionele genesing van die adolessent by te dra. Afgesien van die normale kognitiewe benadering in die terapeutiese gesprekvoering, is dit somtyds nodig om beradingstegnieke van 'n ander aard te gebruik. Dit is in hierdie opsig dat musiek 'n waardevolle rol in die begeleiding van die adolessent kan speel. Andersen (2011) verklaar die mistieke eienskappe van musiek treffend met hierdie woorde: ' Where words fail, music speaks.' Omdat musiek sekere emosies in die adolessent stimuleer, kan dit tydens berading vir die adolessent ' $n$ aanknopingspunt bied om sy of haar eie emosies te herken en te verwoord. Die herkenning en verwoording van emosies is dikwels die eerste stap tot innerlike genesing. Wanneer die adolessent begelei word om sy of haar emosies te herken, kan hy of sy terselfdertyd begelei word om die emosies te verwerk en te hanteer (Anderson, Zeulke \& Zeulke 2000:111). Musiek as 'n beradingstegniek in die pastorale begeleidingsproses bestaan uit die gebruik van musiek en/of elemente van musiek soos ritme, melodie en harmonie (Lotter 2011). Enige soort musiek word in die pastorale begeleidingsproses gebruik, naamlik geestelike en sekulêre, sowel as instrumentale en vokale musiek. Die adolessent word soms ook gevra om sy of haar emosies in lirieke te verwoord, óf deur bestaande lirieke te bespreek óf deur nuwe lirieke te skryf.

Volgens die American Music Therapy Association (2011) kan musiekterapie gedefinieer word as die gebruikmaking van enige musiekintervensie om spesifieke georiënteerde doelwitte te bereik. Dit behels die gestruktureerde gebruik van musiek wat spesifiek ontwerp is as 'n hulpmiddel om die kommunikasie, verhoudings, onderrig, mobilisasie, organisasie en uitdrukkingsvermoë van individue en groepe van alle ouderdomme te fasiliteer en te bevorder, sodat hulle fisiese, emosionele, kognitiewe, verstandelike en sosiale behoeftes vervul kan word. Soos met ander beradingshulpmiddels is die gebruikmaking van musiek nie 'n towerkuns om krisisse onmiddellik op te los nie, maar 'n hulpmiddel om oor 'n lang termyn positiewe verhoudingsvaardighede aan te leer en om ingewikkelde emosies en gevoelens op 'n gesonde wyse uit te druk. Met musiek as ' $n$ beradingstegniek word probeer om die potensiaal in die adolessent te help ontwikkel en om funksies te restoureer wat die adolessent in staat stel om beter intraen interpersoonlike integrasie te bemeester (American Music Therapy Association 2011; Lotter 2011).

Die verhaal van Stacey² (skuilnaam) illustreer hoe musiek 'n deel van die pastorale beradingsproses kan word. Stacey vertel dat sy nooit 'n verhouding met haar vader kon hê nie en dat dit vir haar baie emosionele seer veroorsaak het. Stacey se ouers is geskei terwyl sy nog in die laerskool was en haar pa is 'n paar jaar later oorlede. Ten spyte van talle probeerslae het sy eers emosionele genesing gekry nadat sy haar emosies in 'n liedvorm kon neerskryf en toonset. Hierdie is die woorde van haar liriek:

\section{Carry you in my heart}

\section{Verse}

Although we lived our lives apart Daddy you were everyday in my heart I don't understand the choices you made, But I want you to know that I'll be okay. Chorus

And I wish that I could see you again And I wish that I could have hold your hand And I wish that I could have said goodbye And that your daughter will always Love you

That your daughter will always carry you in her heart Verse

Daddy you left me for the second time And I forgave you for leaving the first

2.Stacey (skuilnaam) is ' $n$ jong vrou in haar twintigerjare wat pastoraal deur die outeurs begelei is in die verwerking van die dood van haar vader. 
I have questioned your decisions all my life But God gave me peace More than enough Chorus Bridge

And I didn't know what I know now I blamed you night and day For this heartache

So I pushed you away almost everyday And I thought it's too late But it's not too late to say: Daddy I'm sorry

For not understanding your heart's ache End

It's not too late no

By Saving Grace oh

My Daddy he left me for the second time

And I also forgave him for leaving me the first.

Vir Stacey het die skryf van hierdie liriek 'n kanaal geword waardeur sy haar emosies kon herken en verwoord, en genesing vir die onderliggende pyn kon vind. Op so 'n manier word musiek eintlik die adolessent se stem wanneer sy of haar eie ontbreek.

Wat Osmer (2008) se model vir die metodologie in die wetenskapsbeoefening van Praktiese Teologie betref, is daar in hierdie punt aandag geskenk aan die empiriese aspek, naamlik die vraag na die invloed van musiek op die lewe van die adolessent. Die volgende afleidings kan uit die bespreking gemaak word:

- Pastorale berading aan die adolessent vereis dat die pastorale berader die adolessent op sy of haar eie vlak sal ontmoet, om sodoende 'n veilige ruimte te skep waarbinne die emosies herken en verwerk kan word.

- Afgesien van die normale kognitiewe benadering in die terapeutiese gesprekvoering is daar gevind dat musiek 'n waardevolle rol vervul in die begeleiding van die adolessent.

- Musiek word die adolessent se taal waarin hy of sy hul emosies kan uitdruk.

\section{Die uitwerking op en bydrae van musiek tot die adolessent se lewe}

Om musiek doeltreffend as hulpmiddel in die pastorale begeleidingsproses te gebruik, is dit noodsaaklik om die uitwerking op en bydrae van musiek tot die adolessent se lewe te verstaan. Vir hierdie doel word daar in die volgende afdeling aandag gegee aan (1) die funksie van musiek in die Bybel, (2) musiek as "n nuwe raam' vir 'n ou foto, (3) die invloed van musiek op die adolessent se emosies en fisiologiese ontwikkeling en (4) die rol van sekulêre musiek in die lewe van die adolessent.

\section{Die funksie van musiek in die Bybel}

Volgens Miller (2011) is die doel van musiek in aanbidding primêr om God te verheerlik. Lofprysings- en aanbiddingsmusiek kan gebruik word om innerlike transformasie in die adolessent mee te bring, omdat dit 'n ontmoeting tussen die adolessent en God bewerkstellig wanneer pastorale tegnieke en woorde kortkom (Elyon 2008:47). Die musiek maak dus die adolessent bewus van God se grootheid en alomteenwoordigheid. God het die gawe van musiek aan die mens gegee om kreatief met Hom en die wêreld in verhouding te tree (Elyon 2008:9). In die Bybel is die positiewe effek van musiek op die gemoed van die mens duidelik sigbaar. Dawid het byvoorbeeld op die harp gespeel om koning Saul te kalmeer (1 Sam 16:14-23) en die apostel Paulus het Christene die opdrag gee om mekaar met musiek te bemoedig (Ef 5:19).

Die musiekterapeut Carol Lotter (2011) wys op die volgende funksies van musiek in die Bybel:

- Dankbaarheid, byvoorbeeld in Eksodus 15:1-7: Nadat God 'n pad deur die waters van die Skelfsee vir Israel oopgemaak het, het die volk 'n lied as dankbetuiging gesing.

- Hartseer en bekommernis, byvoorbeeld in Psalm 88:1-4: Hierdie psalm is ' $n$ lied waarin die outeur sy hartseer en bekommernis voor die aangesig van God bring.

- Twyfel en vrees, soos in Psalm 13:1: Die psalm word as 'gebedsvertroue van Dawid' beskryf. Dawid stel sy hart se vrae aan die Here en lê sy vrese en twyfel voor God neer. Nadat hy dit gedoen het, sê Dawid dat hy op God sal vertrou en tot eer van Hom sal sing.

- Belydenis, byvoorbeeld in Psalm 51: Die psalm word die 'boetelied van Dawid' genoem. Dawid bely sy verkeerde daad met Batseba. Hy vra God om hom te vergewe en 'n rein hart in hom te skep.

- Fisiese en emosionele pyn, byvoorbeeld in Psalm 6:3-4: Dawid vra die Here om hom gesond te maak, want sy gebeente is verskrik. Daar kan afgelei word dat Dawid ook emosionele pyn ervaar het, omdat sy siel ook verskrik is.

- Musiek kan lei tot die ontmoeting tussen God en die mens. 'n Voorbeeld word in 2 Kronieke 5:13-14 gevind: Met die inwyding van die tempel het die trompetblasers en die sangers die Here geloof. 'n Wolk wat die heerlikheid van God simboliseer, het die huis van die Here toe gevul.

- Deurbrake kan plaasvind deur musiek, soos in Handelinge 16:25: Paulus en Silas was in die gevangenis van Filippi gewerp met hul voete in 'n blok. Hulle het begin bid en lofliedere sing, waarna ' $n$ aardbewing al die deure van die tronk oopgeruk het en al die gevangenes se boeie losgeraak het.

Alhoewel die Bybel na die mens as ' $n$ geheel verwys, is die mens 'n multidimensionele wese wat uit verskillende fasette bestaan, naamlik liggaam, gees, emosies en denke (Elyon 2008:27). Musiek spreek tot die hele mens (Maritz \& Dreyer 2002:1218). Daar is ' $n$ ontologiese en epistemologiese verbintenis tussen die mens en musiek. Musiek kommunikeer gelyktydig op die affektiewe, kognitiewe, normatiewe en konatiewe vlakke met die mens. In die voormoderne era is musiek volgens Elyon (2008:38) as 'n holistiese 
realiteitsbegrip beskou. Hy beweer verder (Elyon 2008:114) dat wanneer 'n persoon 'n krisis beleef, lofprysings- en aanbiddingsmusiek hom of haar help om 'n ontvanklike gemoed te verkry. Lofprysing en aanbidding beklemtoon die grootheid en die wonderwerkende krag van God. Die aandag van die persoon wat God loof en prys, verskuif van die krisis na die grootheid en almag van God en stel die persoon in staat om nuwe moed te skep en om sy of haar innerlike emosies te herken en te verwerk. Lofprysing en aanbidding gee nie net gemoedsrus en vrede nie, maar het ook die potensiaal om die mens se verhouding met God te verdiep. Hiervan is die psalms 'n goeie voorbeeld. Die psalms bestaan uit lofprysings- en aanbiddingsliedere en druk verskeie emosies uit - vreugde, lof, smeking, pyn en hulpeloosheid (Burden 1996:754). Die psalms kan gesing, gelees en gebid word. Depressie en angstigheid verander in lof en vreugde wanneer die psalms korrek gebruik word in pastorale begeleiding (Maritz \& Dreyer 2002:1216). Bedroefde mense in die Bybel, soos byvoorbeeld Jeremia en Dawid, het nadat hulle hul klagtes en hartseer singend en spelend aan die Here bekend gemaak het, weer moed en hoop verkry om die lewe aan te pak (Maritz \& Dreyer 2002:1217). Musiek word 'n aanknopingspunt tussen die adolessent en God in pastorale begeleiding, omdat dit ' $n$ vorm van gebed word wat die adolessent toelaat om eerlik met God te kommunikeer oor sy of haar gevoelens (Anastasi 2005:317). Die wete dat God hierdie uitroep, wat deur middel van musiek tot Hom kom, verstaan, dra daartoe by dat die adolessent voel dat hy of sy vir God aanvaarbaar is. Sodoende kan verhoudingsgroei plaasvind.

Met verwysing na Osmer se model vir die metodologie in die wetenskapsbeoefening van Praktiese Teologie is daar in hierdie punt aandag geskenk aan die normatiewe aspekte, naamlik die vraag watter norme uit 'n kort oorsig van die gebruik van musiek in die Bybel afgelei kan word. Die volgende afleidings kan hieruit gemaak word:

- Musiek het die vermoë om 'n ontmoeting tussen God en die adolessent te bewerkstellig sodat innerlike transformasie kan plaasvind.

- In die Bybel word die positiewe effek van musiek op die gemoed van mense en die groot rol wat musiek in mense se lewens speel, duidelik uitgebeeld. Om hierdie rede word gesien dat daar ' $n$ ontologiese en epistemologiese verbintenis tussen musiek en die mens is.

- Lofprysings- en aanbiddingsmusiek dra daartoe by dat die mens wat onder 'n krisis gebuk gaan, weer 'n ontvanklike gemoed kan kry, omdat die musiek hom of haar bewus maak van die grootheid en almag van God.

\section{Musiek: 'n Nuwe raam vir'n ou foto}

Musiek se invloed op die geskiedenis, morele en kulturele kwessies is al vir eeue opgemerk. In die vroeë Christelike era (476-1450 AD) het die priesters musiek gebruik om 'n geestelike ervaring te skep waarin fisiese pyn verwerk en die gevoel van hoop gekweek kon word (Carroll 2011:175). Musiek, die priester en die pasiënt het saam as 'n eenheid gefunksioneer om genesing te bewerkstellig (Carroll
2011:175). Himnes het gedien as die bron van genesing, omdat daar geglo is dat musiek 'n kanaal na die hemel toe open. Musiek het ook die priester en die sieke met mekaar verbind. Die priester word voorgestel as 'n liefdevolle vader wat die siek mens as 'n swakkeling en 'n sterwende wese wat gered moet word, beskou. Himnes is gesing om genesing te bevorder en om die boodskap van hoop aan die sieke oor te dra. Die sieke was nederig en dankbaar vir 'n liefdevolle God wat aan hom of haar genesing wil gee. Carroll (2011) brei verder hieroor uit:

Music has been used as a means of communication and healing since the beginning of mankind. Music Therapy, which involves the music therapist, the client and the music in an ever-evolving relationship, is rooted in the ancient literate societies. (p. 171)

Deur die eeue is musiek ook gebruik as 'n geneesmiddel om die lyding van mense te verlig (Le Roux 2006:1). Die Grieke en Romeine het geglo dat musiek towerkrag besit om die liggaam en siel se pyn te genees. Die gebruik van musiek in genesingsrituele kom uit die antieke tyd. Musiek gekombineer met danse, woorde en musiekinstrumente was 'n aanvaarde en doeltreffende manier om siekte en wonde te genees (Halpern 2011). Tydens die Eerste Wêreldoorlog is fonograwe in hospitale geplaas nadat daar waargeneem is dat musiek nie net die pasiënte vermaak het nie, maar ook 'n ontspannende effek op hul emosionele toestand gehad het (Halpern 2011). Fonograwe is aanvanklik in operasiesale gebruik, spesifiek as 'n psigiese hulpmiddel vir dokters. Daar is egter opgemerk dat die pasiënte ook voordeel daaruit put deurdat hulle die narkose makliker te bowe gekom het en nie soveel pynmedikasie ná die operasies gevra het nie (Halpern 2011).

In die twintigste eeu is musiek egter vir die eerste keer formeel as ' $n$ vorm van terapie vir begeleiding tot emosionele genesing nagevors en sodoende het Musiekterapie as dissipline ontstaan (Le Roux 2006:1). Volgens Le Roux (2006:4) is daar veral drie eienskappe van musiek wat genesingskrag het, naamlik die nabootsende effek, die bewegende vorm en die suiwerheid daarvan. Melodie, poësie en dans vorm 'n eenheid wat die siel penetreer; daarom is die lirieke en musiekvideo's 'n belangrike deel van musiekterapie (Le Roux 2006:3). Die lirieke en video's dra 'n bepaalde boodskap aan die wêreld oor van hoe daar onder andere geleef moet word en wat nagestreef moet word. Dit het 'n bepaalde invloed op mense se sienings en gedragspatrone (Kistler et al. 2010:617). Le Roux (2006:4) som hierdie beïnvloeding op met die woorde dat musiek 'n 'nuwe raam aan 'n ou foto gee'.

\section{Die invloed van musiek op die adolessent se emosies en fisiologiese ontwikkeling}

Volgens Le Roux (2006:1) is daar 'n belangrike verband tussen musiek en die adolessent se emosies, omdat musiek oor die krag beskik om verby die verstand te beweeg. Die belangrikste vraag waaroor daar in hierdie verband in die navorsing gedebatteer word, is of musiek die emosionele toestand van die adolessent beïnvloed en of die adolessent se emosionele toestand sy keuse van musiek beïnvloed 
(Thompson 2009). Daar bestaan veral twee uiteenlopende sienings, naamlik:

- Die cognitivist position gee voorkeur aan die siening dat adolessente wel sensitief vir musiek is en die emosie in die musiek kan identifiseer, maar dat die musiek nie 'n invloed op sy of haar emosionele toestand het nie.

- Die emotivist position is van mening dat musiek 'n emosionele reaksie by die adolessent ontlok. Hieroor word egter baie geredeneer, omdat daar geglo word dat musiek emosie uitdruk, eerder as om dit te produseer (bl. 143).

Uit Bybelse voorbeelde blyk dit egter dat albei sienings geldig is. Die cognitivist position word ondersteun waar daar ná oorwinnings lofgesange van blydskap tot God gesing word (vgl. Ps 18 en 68). Die emotivist position se siening kom weer na vore in 1 Samuel 16:14-23, waar dit blyk dat musiek kalmte in Saul se gemoed gebring het. Hieroor beweer Anastasi (2005) die volgende:

Music moves people. Anyone who has ever listened to good music understands that music has a way of bypassing the walls of the intellect and targeting the emotions, often demanding some type of a response. Combined with poignant lyrics, music can manipulate emotions and evoke tears, regret, anger, happiness, a sense of social responsibility etc. (p. 311)

Volgens Le Roux (2006:33) toon alle mense spesifieke breinpatrone ten opsigte van die verskillende emosies wat hul ervaar, en hy sê dat die genesingskrag van musiek juis in die vermoë lê om emosionele ondervindings te ontlok. Emosionele beklemtoning is ' $n$ wyse van kommunikasie wat gesigsuitdrukking, gebare en vokalisering (woorde, stemtoon en stemverbuiging) insluit (Graham 2011:1). Musiek stel die individu in staat om sy of haar eie stemhelling, stemtoon en ritme te moduleer om emosies doeltreffend uit te druk (Le Roux 2006:33). Lincoln (2005:400-402) wys ook op die moontlikheid dat musiek gebruik kan word om gestalte aan die adolessent se gevoelens te gee. Gevolglik dien musiek as die stem van emosionele pyn, omdat dit emosies uitdruk wat nie met woorde beskryf kan word nie. Om innerlike genesing te laat plaasvind, moet die adolessent sy of haar pyn en lyding uitdruk, en daarvoor benodig hy of sy 'n taal waarin die emosies gekommunikeer kan word (Anastasi 2005:303-309). In baie gevalle word musiek die adolessent se emosionele taal. Adolessensie is ' $n$ tydperk in die mens se lewe wat by uitstek deur emosionele skommelinge gekenmerk word (Erasmus \& De Klerk 2002:348). Dit is 'n tydperk van storm en drang, maar daar kan ook kalmte en stabiliteit na vore kom. Identiteitsvorming vir die adolessent is moeilik, omdat konflik en probleme in hierdie tydperk van ontwikkeling algemeen voorkom. Dit bring innerlike emosionele worsteling mee wat die adolessent kognitief nie kan begryp nie, en die emosionele onstabiliteit kan tot neerslagtige gevoelens lei (Erasmus \& De Klerk 2002:348). Omdat adolessente se emosies voortdurend fluktueer, kan die gestruktureerde gebruik van musiek in pastorale begeleiding tot emosionele stabiliteit bydra. Adolessente kan musiek immers gebruik om hul emosies te ondersoek en te verwoord (Danley-Smith \& Patey 2003:7-8).

Volgens Mueller (2011) beskryf die sekulêre musiekster Kanye West die invloed van musiek op mense se lewens soos volg: 'The music we make, is the soundtrack to our lives, and these are the visuals that influence our culture.' Mueller (1999:67) is oortuig dat musiek 'n groot invloed op die adolessent se lewe het, omdat dit wat hulle hoor en sien aan hulle identiteit, kleremodes, seksualiteit en spiritualiteit skaaf. Musiek is 'n samebindende faktor in jeugkultuur. Groepsidentiteit is nie alleen 'n resultaat van musiek nie, maar dit word ook gebruik as 'n medium waardeur individuele identiteit gerekonstrueer, beklemtoon en getransformeer word (Lincoln 2005:400-401). Die musiekmedia is ' $n$ belangrike bron van informasie en raadgewing oor besluitneming in identiteitsvorming, en populêre musiek is oorheersend tydens adolessensie (North et al. 2000:257-258). Musiek is die gewildste medium om ledige ure te vul en baie tieners sien musiek as een van hul belangrikste aktiwiteite. Die voorkeur vir musiek tydens die tienerjare groei uit die moontlikheid om deur middel van musiek dringende ontwikkelingskwessies aan te roer (North et al., 2000:257-258). Die probleme tydens hierdie ontwikkelingstadium is onder andere die bemeestering van norme en waardes, sodat verantwoordelike gedrag, emosionele onafhanklikheid en volwasse verhoudings sal seëvier (Lotter 2005:24).

In die algemeen kan musiek die manier hoe adolessente voel, dink en optree, verander, veral omdat hulle gewoonlik in afsondering na musiek luister (North et al. 2000:260). Sodoende skep adolessente vir hulself 'n veilige hawe in hul binnekamers waar hulle die gebroke wêreld ontvlug (Lincoln 2005:402). Om na musiek te luister, word vir adolessente een van die belangrikste oorlewingstrategieë in moeilike lewensituasies. Dit bring verligting in hoofsaaklik drieërlei opsig, naamlik die tempering van ongewenste buie, vertroosting en versterking in die hantering van hulle persoonlike probleme en 'n katarsis in hulle verhouding tot negatiewe emosies (Marinda \& Claes 2009:217). Vanuit 'n pastorale begeleidingsoogpunt is die onttrekking in afsondering ongewens, maar dit help tog dat die adolessent sy of haar emosies kan begin herken en verwoord, sodat dit later in die beradingsessies hanteer kan word. Lincoln (2005:413) beweer dat die wyse waarop die adolessent musiek gebruik, bepaal word deur sy of haar gevoelens op elke gegewe tydstip, aktiwiteite waarby hy of sy betrokke is en sy of haar sosiale lewe. Lincoln (2005:405) is verder van mening dat adolessente na musiek luister omdat dit hulle die krag gee om die spesifieke atmosfeer te skep wat hulle op 'n spesifieke tydstip begeer en benodig. Dit is juis om hierdie redes dat musiekintervensie doeltreffend is in die pastorale begeleiding van die adolessent. Deur musiek in die pastorale begeleidingsproses in te sluit, word die adolessent begelei om musiek nie langer as 'n metode van ontvlugting van die werklikheid te gebruik nie, maar om dit aan te wend om die emosionele pyn te verwoord, ' $n$ handeling wat tot die verwerking van die pyn bydra. Ter Bogt et al. (2011) stel dit soos volg: 
Most people appreciate music as enriching and invigorating life. In particular, young people report that music is a crucial medium. They tend to appreciate music's entertaining qualities, and also use this medium to help face the developmental challenges characteristic for their phase of life. Authors studying the role of music in adolescents' lives have even referred to it as 'equipment for living'. Music listening is used as a technique for mood management, and, hence, the medium may help to deal with internalizing problems, such as depression and anxiety, or to cope with feelings of alienation and anger. (p. 148)

Die biomediese teorie van musiek veronderstel dat die brein die middelpunt van beheer oor die menslike liggaam is (Le Roux 2006:38). Musiekintervensie kan dus 'n invloed op die mens se neuropsigologiese struktuur uitoefen, omdat die breingolwe volgens die ritme van die musiek ingestel word wanneer daar na musiek geluister word (Le Roux 2006:9-11). Hierdie ritmiese vloeikrag beïnvloed gedragsfunksies op neurobiologiese gebied. Musiek kan die aksie van die brein verander en sodoende tot kognitiewe, emosionele en sosiale rehabilitasie bydra (Frank 1995:10; Le Roux 2006:9-11). Depressie en angstigheid is moontlik 'n groot probleem onder adolessente wat met onverwerkte emosies sukkel. Kortisol is die peptied wat depressiewe emosies ontlok. Te veel kortisol lei tot die verswakking van die immuunsisteem en sodoende word die liggaam blootgestel aan siekte (Jensen 2000:66; Le Roux 2006:42). Die liggaam se stresreaksie kan gereguleer word deur na musiek te luister en op die manier word immuniteit verhoog en gesondheid bevorder. Hierdie fisiologiese elemente het 'n verdere uitwerking op die psigiese en fisiese gesondheid van die adolessent (Jensen 2000:64-66). Musiek wat aangewend word om die biomediese toestand te verander, bring gelyktydig ' $n$ verandering in die psigososiale veld mee (Le Roux 2006:9-11). Daar word beweer dat daar 'n verband tussen die psigososiale veld en biomediese veld is; dus is die brein die sleutel tot die manier waarop musiek geprosesseer word. Enersyds kan sekere musieksoorte die brein aktiveer en stimuleer om positiewe emosies, byvoorbeeld vrede of opgewondenheid, na vore te bring, terwyl ander musieksoorte 'n kalmerende effek op die adolessent het (Amen 2010:213). Andersyds kan verskillende tempo's en ritmes verskillende uitwerkings op die fisiologie van die adolessent hê.

Dr Frances le Roux (2006:103-112) toon in haar boek Music is Healing aan watter tipes musiek bepaalde funksies in die mens verrig. Sy onderskei onder andere die volgende: ${ }^{3}$

- Musiek wat depressie verlig, is onder andere Beethoven se 'Mis in C majeur' (Mass in C major) en die 'Aan die mooi blou Donau' (Blue Danube Waltz) van Strauss.

- Musiek om die immuunsisteem te verbeter, is 'Die Magnificat in D majeur' (The Magnificat in D major) van Bach. Magnificat is die Latynse woord vir loflied, 'Die loflied van Maria'.

3.Met die luister na hierdie tipe musiek kan gevra word of dit die tipe musiek is waarna adolessente sou luister. Die gebruikmaking van musiek in die pastorale begeleiding van die adolessent word breedvoeriger onder 'Musiek as ' $n$ deel van die pastorale begeleidingsproses van die adolesseent' bespreek.
- Om aandag van pyn af te trek, kan Haydn se 'Sewe laaste woorde van Christus' (Seven Last Words of Christ) of Mozart se 'Mis in C mineur' (Mass in C minor) help.

- Musiek wat energie vrystel en as 'n stimulant kan dien, is Verdi se 'Die Slawekoor' uit die opera Nabucco (Nabucco Hebrew Song) en 'Simfonie nommer 3 in E-mol majeur opus 55' (Symphony nr. 3) van Beethoven.

- Brahms se 'Wiegelied' (Lullaby) en Schumann se 'Kind wat insluimer' uit die 'Kindertonele opus 15' (Child Falling Asleep) is 'n teenmiddel vir insomnia.

- 'Vyf fluitkonserte' (Five Concerti for Flute) van Vivaldi en 'Simfonie in A majeur' (Symphony in A major) van Mozart help vir beter konsentrasievermoë.

\section{Die rol van sekulêre musiek in die lewe van die adolessent}

Amen (2010:214) en Le Roux (2006:112) is albei van mening dat sekere sekulêre musiekgenres adolessente negatief beïnvloed. Heavy metal, rap en lirieke vol haat lei nie net tot gedragsprobleme nie, maar ook tot dwelmgebruik en vroeë seksuele aktiwiteite. Adolessente moet ingelig word oor die uitwerking wat sekere musiekgenres op die brein en ander fisiologiese funksies het. Le Roux (2006:112) stel dit soos volg: 'Meaningless music is to the mind as unhealthy as junk food is to the body.

Talle adolessente wend hulle na musiek as 'n vorm van selfmedikasie (Jensen 2000:64-66). Soos aangetoon in die beskrywing tot dusvêr is musiek in staat om die liggaam te genees of te vernietig (Le Roux 2006:34). Die struktuur van musiek en die kommunikatiewe waarde van musiek speel ' $n$ betekenisvolle rol in hierdie opsig. Daar is bevind dat die ingewikkelder strukture van klassieke musiek geneig is om intenser emosies te ontlok as gewone sekulêre musiekstrukture (Le Roux 2006:34). Die vraag kan dus nou ontstaan of alle sekulêre musiek nadelig is. Anastasi (2005) beweer:

While acknowledging the risk that they (adolescents) will be moved by the wrong things and in the wrong direction, God can use pop music with lyrics of lamentation to start, or continue, the process of healing. (p. 313)

Anastasi (2005:313-317) noem dat sekulêre musiek gedagtes, idees en gevoelens kommunikeer waarmee die adolessent hom of haar kan assosieer. Die musiek skep lirieke wat die ware kwesbare innerlike blootstel en wat die krag dra om die luisteraar uit te nooi vir assosiasie en deelname. Daar is gevind dat lirieke saam met hartseer of angry musiek intenser emosies laat opwel, as lirieke saam met vrolike musiek (Ali \& Peynircioglu 2006:530). Omdat musiek die geleentheid vir emosionele ontlading bied, kan die adolessent van negatiewe emosies bevry word (Anastasi 2005:317). Musiek met intense lirieke en ritmes verhoog die adolessent se emosionele vlak, omdat dit die onderdrukte emosies losmaak en laat uitbars.

Wat Osmer se model vir die metodologie in die wetenskapsbeoefening van Praktiese Teologie betref, is daar in hierdie punte aandag geskenk aan die interpretatiewe 
aspekte, naamlik die vraag waarom musiek so 'n groot invloed op die lewe van die adolessent het. Die volgende afleidings kan hieruit gemaak word:

- Regdeur die eeue is musiek wat met danse, woorde en musiekinstrumente gekombineer is, as 'n doeltreffende medium gebruik om siekte en wonde te genees. In die twintigste eeu is begin om musiek as 'n deel van die terapeutiese begeleidingsproses met die oog op emosionele genesing na te vors. Daar is bevind dat die lirieke en musiekvideo's bepaalde boodskappe aan die wêreld oordra van hoe daar onder andere geleef moet word en wat nagestreef moet word.

- Navorsing toon dat daar 'n belangrike verband tussen musiek en die adolessent se emosies is, omdat musiek oor die krag beskik om verby die verstand te beweeg en aan sy of haar emosies gestalte te gee.

- Musiek het 'n groot invloed op adolessente se lewens, omdat dit wat hulle hoor en sien aan hulle identiteit, kleremodes, seksualiteit en spiritualiteit skaaf. Dit is 'n samebindende faktor van jeugkultuur. Die musiekmedia is ' $n$ belangrike bron van informasie en raadgewing oor besluitneming in identiteitsvorming, en populêre musiek is oorheersend tydens adolessensie. Die probleme tydens die ontwikkelingstadium is onder andere om norme en waardes te bemeester, sodat verantwoordelike gedrag, emosionele onafhanklikheid en volwasse verhoudings sal seëvier.

\section{Musiek as'n deel van die pastorale begeleidingsproses van die adolessent}

Wanneer musiek as 'n deel van die pastorale beradingshulpverleningsproses gebruik word, is daar sekere aspekte wat belangrik is. In die eerste plek hoef die pastorale begeleier geen verskoning aan te bied oor die keuse van die musiekgenre wat gebruik word nie, omdat die musiek gestruktureerd vooraf gekies word om aan die doel van die berading te voldoen. 'n Ander musiekgenre as waarna die adolessent gewoonlik luister, sal juis bydra dat hy of sy uit sy of haar gemaksone tree. Dit is bevorderlik vir die herkenning van emosies (Lotter 2011). Tweedens meld Le Roux (2006:101) dat die brein 'gewoond' raak aan die musiek as daar gereeld na 'n spesifieke musiekgenre geluister word. Dit het tot gevolg dat die verlangde resultate nie verkry word nie (Le Roux 2006:101). In die pastorale begeleiding neem musiek die sentrale posisie in, want die musiek is die stimulus waardeur verandering in die adolessent gekanaliseer word; in die begeleiding neem kliënte deel aan musiekaktiwiteite om verandering te bemeester (Maritz \& Dreyer 2002:1210).

Die pastorale berader kan hom of haar nie van die musiekintervensie afsny nie (Lotter 2011); inteendeel, hy of sy speel 'n sleutelrol omdat hy of sy daarvoor verantwoordelik is om toepaslike musiek vooraf te kies om bepaalde probleemsituasies op te los. Soos reeds genoem, is musiekterapie 'n wye en kreatiewe veld. Lirieke, musiekinstrumente, volume, ritme ensovoorts kan gebruik word om onderdrukte emosies te hanteer. Musiekterapie is 'n vorm van expressive terapie, omdat dit die moontlikheid bied om aan die self uiting te gee. Rudlin (2011) stel voor dat musiek as terapie vir die adolessent in die pastorale beradingsproses op die volgende wyse toegepas word:

- Die adolessent gee uiting aan sy of haar emosies wanneer hy of sy die woorde van 'n lied saamsing.

- Rustige musiek sal help dat die adolessent ontspan.

- Om 'gewelddadige' lirieke te bespreek, is 'n kreatiewe wyse om woede te kommunikeer.

- Die depressiewe adolessent kan na opgewekte ritmiese musiek luister, waarna die emosies wat hy of sy beleef het, bespreek kan word.

- Adolessente kan nuwe woorde vir 'n lied skryf. Dit kan help om gevoelens uit te druk, te evalueer en te identifiseer.

Lotter (2011) gee praktiese riglyne wat in gedagte gehou moet word wanneer musiek in die pastorale beradingsopset gebruik word:

- Musiekterapie is 'n kliëntgesentreerde benadering. Wanneer musiek dus as 'n beradingstegniek gebruik word, moet die adolessent toegelaat word om sy of haar eie innerlike wysheid en insig te vertrou en daarin begelei word.

- Daar moet gewerk word met wat voorhande is. Daar kan net gewerk word met die materiaal wat die adolessent vir die pastorale berader gee. Die adolessent sal stelselmatig ander deure begin oopmaak as hy of sy voel dat genesing begin intree. Die pastorale begeleier moet die adolessent nie na ' $n$ volgende fase druk nie. Die begeleiding van die adolessent na innerlike genesing bly'n proses.

- Musiek dien as die 'medeberader'. Deur die musiek word 'n weg gebaan sodat die onderdrukte emosies na die oppervlak gebring word.

- Die pastorale berader moet gemaklik wees wanneer daar stilte tydens die beradingsessie is en die adolessent toelaat om sy of haar emosies te ontgin.

- Die pastorale berader moet nooit namens die adolessent sy of haar emosies interpreteer nie, maar slegs die proses fasiliteer en oop en ondersoekende vrae stel.

- Ander beradingstegnieke soos kognitiewe terapie en die terapeutiese gesprek, of hulpmiddels soos klei of prente, word en kan ook in die begeleidingsproses gebruik (word). Die beginsel is om kreatief te wees en die adolessent op sy of haar vlak te ontmoet.

Opsommend kan gesê word dat die pastorale begeleiding waarvan musiek 'n deel vorm, uit die terapeut én die adolessent bestaan, en dat albei onder andere musiek of elemente van musiek gebruik om saam te werk met die oog op 'n genesingsdoelwit. Lotter (2011) beklemtoon dat hierdie begeleiding uiteindelik nie probleemgesentreerd is nie, maar streng toegespits is op die innerlike genesing van die adolessent. Die adolessent moet aangemoedig word om op sy of haar eie instinkte te vertrou. As dit slaag, het die proses van genesing reeds begin.

Met verwysing na die model van Osmer vir die metodologie in die wetenskapsbeoefening van Praktiese Teologie is daar 
aan hierdie punte aandag geskenk aan die pragmatiese aspekte, naamlik die vraag hoe die pastorale berader musiek as ' $n$ deel van die pastorale begeleidingsproses moet aanwend. Die volgende afleidings kan hieruit gemaak word:

- Wanneer die pastorale berader musiek 'n deel van die pastorale begeleidingsproses maak, moet hy of sy die bepaalde intervensie vooraf op 'n gestruktureerde manier beplan.

- Musiek as 'n vorm van expressive terapie word die stimulus wat verandering in die adolessent laat begin.

\section{Gevolgtrekking}

Die pastorale begeleiding van die adolessent op die pad na innerlike genesing moet met groot sorg en wysheid geskied, omdat die adolessent se selfkonsep in hierdie tydperk gevorm word. Die gebruikmaking van musiek tydens die pastorale begeleidingsproses is uiteindelik ook 'n deel van kognitiewe gedragsterapie, wat daardeur gekenmerk word dat die vernuwing van denke ' $n$ verandering in gedrag tot gevolg het. Die nuwe insigte waartoe die adolessent kom deur die herkenning en verwerking van die onderdrukte emosies dra daartoe by dat sy of haar denke dienooreenkomstig verander of vernuwe word. Vanuit'n Christelike perspektief is die kognitiewe gedragsterapie 'n waardevolle deel van die innerlike genesingsproses. Soos wat die adolessent sy of haar emosies deur musiek begin herken en verwerk, vind daar diepgaande innerlike genesing van die negatiewe emosies plaas. Adolessente word begelei in die verbetering van hul vermoë om hul emosies op 'n sinvolle en opbouende manier te herken en uit te leef, asook om afstand te doen van die soeke na erkenning en waardering van sy of haar verkeerde gedragspatrone. Uit die navorsing blyk dit dat die pastorale begeleiding van die adolessent ' $n$ groot uitdaging is, omdat adolessensie ' $n$ tydperk is wat deur emosionele skommelinge gekenmerk word. Dit is in hierdie tydperk van die individu se lewe dat hy of sy 'n eie identiteit begin vorm en na 'n eie plek in die samelewing soek - onafhanklik van die beskermde grense van hul ouerhuis. Dikwels beskik adolessente nie oor die vaardighede om hul onderdrukte en onverwerkte emosies te verwoord nie. Uit die navorsing blyk dit dat musiek al baie eeue in die genesingsproses gebruik word en dat dit 'n groot invloed op die psige van die mens kan uitoefen. Gevolglik kan musiek baie doeltreffend in die pastorale begeleidingsproses van die adolessent gebruik word. Dit behels die gebruikmaking van musiek en/of elemente van musiek soos ritme, melodie en harmonie op 'n gestruktureerde manier om bepaalde uitkomste te verkry.

\section{Erkenning \\ Mededingende belange}

Die outeurs verklaar dat hulle geen finansiële of persoonlike verbintenis het met enige party wat hulle nadelig kon beïnvloed in die skryf van hierdie artikel nie.

\section{Outeursbydrae}

Albei outeurs het meegedoen aan die navorsing en A.L.d.P. (Noordwes-Universiteit) het die artikel in finale vorm gereed gemaak vir indiening.

\section{Literatuurverwysings}

Ali, S. \& Peynircioglu, F., 2006, 'Songs and emotions: Are lyrics and melodies equal partners?', Psychology of music 34(4), 511-534. http://pom.sagepub.com/ content/34/4/511

Amen, D.G., 2010, Change your brain, change your life: The breakthrough programme for conquering anger, anxiety, obsessions and depression, Piatkus, London.

American Music Therapy Association, 2011, What is music therapy?, viewed 12 July 2011, from http://www.musictherapy.org

Anastasi, A.P., 2005, 'Adolescent boys' use of emo music as their healing lament', Journal of religion and health 44(3), 303-319. http://dx.doi.org/10.1007/s10943005-5467-9

Andersen, H.C., 2011, Quotes from Hans Christain Andersen, viewed 12 July 2011, from http://www.goodreads.com/quotes/90636-where-words-fail-music-speaks

Anderson, N.T., Zeulke, T.E. \& Zeulke, J.S., 2000, Christ centred therapy: The practical integration of theology and psychology, Zondervan, Grand Rapids.

Burden, J., 1996, 'Psalms', in W. Vosloo \& F.J. van Rensburg (reds.), Die Bybel in praktyk, bl. 754, Christelike Uitgewersmaatskappy, Vereeniging.

Carroll, D., 2011, 'Historical roots of music therapy: A brief overview', Revista do Núcleo de Estudos e Pesquisas Interdisciplinares em Musicoterapia, Curitiba 2(1), 171-178.

Collins, G.R., 1988, Christian counselling: A comprehensive guide, NavPress, Colorado Springs.

Danley-Smith, R. \& Patey, H.M., 2003, Music therapy: Creative therapies in practice, SAGE publications, London.

Elyon, J.R., 2008, 'Die rol van musiek as heelbrein strategie by innerlike verandering: ' $n$ Prakties-teologiese studie', PhD thesis, Fakulteit Teologie, Noordwes-Universiteit.

Erasmus, J.A. \& De Klerk, B.J., 2002, 'Perspektiewe vanuit die psigologie en sosiale wetenskappe vir kerklike bediening aan die adolessent: 'n Ondersoek na die ontwikkeling van die adolessent', Verbum et ecclesia 23(2), 343-352. http:// dx.doi.org/10.4102/ve.v23i2.1200

Frank, J., 1995, Door of hope: Recognizing and resolving the pains of your past, Thomas Nelson, Nashville.

Graham, S., 2011, 'The effect of music therapy on the emotional expressivity on children and adolescents who have experienced abuse or neglect', Masters of Music Therapy, College of Music, Florida State University.

Halpern, S., 2011, The history of music: Spectrum suite, viewed 01 July 2011, from http://www.macalester.edu

Jensen, E., 2000, Music with the brain in mind, Brain Store, San Diego.

Kistler, M., Rodgers, K.B., Power, T., Austin, E.W. \& Hill, L.G., 2010, 'Adolescents and music media: Toward an involvement-mediational model of consumption and self-concept', Journal of Research on Adolescence 20(3), 616-630. http://dx.doi. org/10.1111/j.1532-7795.2010.00651.x

Le Roux, F., 2006, 'Die effek van musiek op die immuunsisteem, emosies en longfunksies tydens die standaard terapeutiese behandeling van spesifieke longpatologie', PhD thesis, Departement van Geneeskundige mikrobiologie, Universiteit van Stellenbosch.

Lincoln, S., 2005, 'Feeling the noise: Teenagers, bedrooms and music', Leisure Studies 24(4), 400-402. http://dx.doi.org/10.1080/02614360500199544

Lotter, C.B., 2005, 'Circles of courage: Music therapy with adolescents in conflict with the law at a community based setting', MMus thesis, Faculty of Humanities, Universiteit van Pretoria.

Lotter, C.B., 2011, 'Music as a resource for pastoral counselling', paper delivered at the Pastoral counsellors in music therapy conference, Rosebank, Johannesburg, 11 August 2011

Marinda, D. \& Claes, M., 2009, 'Music listening, coping, peer affiliation and depression in adolescence', Society for Education, Music and Psychology Research 37(2), 215233. http://dx.doi.org/10.1177/0305735608097245

Maritz, J.F. \& Dreyer, T.F.J., 2002, "n Ondersoek na die aanwending van musiek as hulpmiddel in pastorale terapie binne 'n gespreksmodel', Hervormde Teologiese Studies 58(3), 1208-1220. http://dx.doi.org/10.4102/hts.v58i3.595

Miller, S., 2011, 'Christene en sekulêre musiek: Besprekingsgroep', viewed 01 May 2011, from http://sethdavidmiller.com

Mueller, W., 1999, Understanding today's youth culture: For parents, teachers and youth leaders, Tyndale House, Wheaton.

Mueller, W., 2011, 'Tieners en populêre musiek: Besprekingsgroep', viewed 26 May 2011, from http://www.cpyu.org

North, A.C., Hargreaves, D.J. \& O'Neil, S.A., 2000, 'The importance of music to adolescents', British Journal of Education Psychology 70, 255-272. http://dx.doi. org/10.1348/000709900158083, PMid:10900782

Osmer, R., 2008, Practical theology: An introduction, Eerdmans, Grand Rapids.

Robbins, D., 2004, This way to youth ministry: An introduction to the adventure, Zondervan, Grand Rapids.

Rudlin, K., 2011, 'Music therapy for troubled teens', viewed 25 March 2011, from http://www.parentingteens.about.com

Ter Bogt, T., Mulder, J., Raaijmakers, Q. \& Gabhainn, S., 2011, 'Moved by music: A typology of music listeners', Psychology of Music 39(2), 147-163. http://dx.doi. typology of music listeners', Psych
org $1177 / 0305735610370223$

Thompson, W.F., 2009, Music, thought and feeling: Understanding the psychology of music, Oxford University Press, New York.

Wright, H.N., 2003, Crisis and trauma counselling, Regal Publishing, Ventura. 